TITLE:

\title{
Mirror self-recognition: a review and critique of attempts to promote and engineer self-recognition in primates.
}

$\operatorname{AUTHOR}(S)$ :

Anderson, James R; Gallup, Gordon G

\section{CITATION:}

Anderson, James R ... [et al]. Mirror self-recognition: a review and critique of attempts to promote and engineer self-recognition in primates.. Primates 2015, 56(4): 317-326

\section{ISSUE DATE:}

2015-10

URL:

http://hdl.handle.net/2433/202619

\section{RIGHT:}

The final publication is available at Springer via http://dx.doi.org/10.1007/s10329-015-0488-9.; The full-text file will be made open to the public on 04 September 2016 in accordance with publisher's 'Terms and Conditions for Self-

Archiving'.; This is not the published version. Please cite only the published version.; この論文は出版社版でありません 。引用の際には出版社版をご確認ご利用ください。 
1 Mirror self-recognition: A review and critique of attempts to promote and engineer self-recognition in primates

3

4 James R. Anderson, Gordon G. Gallup, Jr.

5

6

7 Corresponding author: James R. Anderson, Department of Psychology, Kyoto

8 University Graduate School of Letters, Yoshida-honmachi, Sakyo, Kyoto 606-8501,

9 Japan

10 Email: j.r.anderson@psy.bun.kyoto-u.ac.jp

11 Phone \& fax: +81-75-753-4901

12

13 Gordon G. Gallup, Jr. Department of Psychology, State University of New York at 14 Albany, Albany, NY 12222, USA

15

16

17

Short title: Mirror self-recognition in primates

18

19

20

21

22

23

24

25 


\section{Abstract}

29 We review research on reactions to mirrors and self-recognition in nonhuman

30 primates, focusing on methodological issues. Starting with the initial demonstration in

31 chimpanzees in 1970 and subsequent attempts to extend this to other species, selfrecognition in great apes is discussed with emphasis on spontaneous manifestations of mirror-guided self-exploration as well as spontaneous use of the mirror to investigate

34 foreign marks on otherwise nonvisible body parts - the mark test. Attempts to show self-recognition in other primates are examined with particular reference to the lack of convincing examples of spontaneous mirror-guided self-exploration, and efforts to engineer positive mark test responses by modifying the test or using conditioning lesser apes - gibbons and siamangs - are capable of mirror self-recognition.

Keywords: Great apes, lesser apes, monkeys, self-recognition, awareness, mirror- 


\section{Introduction}

52 The demonstration of visual self-recognition in chimpanzees (Gallup 1970) prompted

53 sustained interest and controversy in the field of comparative psychology. The

54 knowledge that humans’ nearest evolutionary relatives are sufficiently self-aware to

55 be able to understand how they look from another visual perspective (i.e., their

56 reflection in a mirror) helped pave the way for important empirical and theoretical

57 developments, including experimental approaches for assessing theory of mind in

58 great apes (Premack and Woodruff 1978). Like theory of mind, however, self-

59 recognition continues to be a contentious issue among anthropologists, biologists,

60 philosophers and psychologists. Some authors resist the idea that the capacity for self-

61 recognition is not uniquely human, raising methodological issues (e.g., Heyes 1994).

62 However, methodological refinements along with empirical and theoretical advances

63 have led to repeated replication and confirmation of the capacity for self-recognition

64 in great apes (Gallup et al. 1995; Povinelli et al. 1997). Gallup (1970) also reported

65 that, unlike chimpanzees, macaque monkeys showed no evidence of self-recognition;

66 he concluded that: "the capacity for self-recognition may not extend below man and

67 the great apes” (p. 87). This proposal has stimulated many attempts to find self-

68 recognition in other species; indeed some authors have gone to extraordinary lengths

69 in an effort to marshall support for continuity in cognitive capacities among species.

70 The alternative view -- that fundamental qualitative differences in cognition might

71 have evolved within the Primate order, including self-awareness, has been repeatedly

72 challenged. Here, we review the history of research on responses to mirrors and self-

73 recognition in nonhuman primates, with special reference to recent claims for mirror

74 self-recognition in non-great ape species. 
Perhaps just as significant as the evidence for self-recognition in chimpanzees

in Gallup’s (1970) original study was the absence of such evidence in macaque monkeys tested under identical conditions. When first confronted with their reflections, both chimpanzees and macaques reacted as if they were in the presence of an unfamiliar conspecific - a reaction that is typical of most visually capable organisms (Gallup 1968; Anderson 1994). But whereas chimpanzees soon started to use the reflection to carefully explore parts of their body that they could not normally see, such as looking inside their mouth, removing mucous from the corner of an eye, or investigating their ano-genital area (Fig. 1), similar spontaneous mirror-guided self-exploration was never observed in macaques; the latter continued to direct social responses towards the reflection, or simply ignored it as they habituated to the presence of the "other monkey."

After 10 days of mirror exposure, the chimpanzees and monkeys were anesthetized and marked on their forehead and an ear using a nonirritant, odorless dye. Upon recovery from anesthesia, in the absence of the mirror neither apes nor monkeys made any effort to touch the marks, which confirmed that they were unaware of their presence. When the mirror was reinstated, however, chimpanzees but not macaques used the reflection to guide their fingers to the marks, which they then investigated. This behavioral difference confirmed that the apes, but not the monkeys, understood that the source of the individuals reflected in the mirror was themselves, corroborating self-recognition seen in the apes' spontaneous mirror-guided self-exploration. In addition, after touching the marks, the apes often examined and sniffed their fingers, in an apparent attempt to gain further information about the strange marks that could only be seen in the mirror. 
Following Gallup’s (1970) report, two lines of primate research on the broad

100

101

102

103

104

105

106

107

108

109

110

111

112

113 head, a similar mark was made on a directly visible area, such as the wrist. This

123 procedure provided a logical means to discount a lack of curiosity and motivation to topic of "mirror-image stimulation and self-recognition" emerged. One aimed to extend knowledge about self-recognition in great apes - its ontogenetic and phylogenetic distributions, its relationship to other manifestations of self-awareness, and factors influencing its expression. The other approach was was characterized by many investigations of the responses of other primate species to mirrors, often including tests for self-recognition. Below we review both lines of research.

\section{Self-recognition in chimpanzees and orangutans}

To test the hypothesis that visual self-recognition would be shared with another species of primates, Lethmate and Dücker (1973) presented a mirror to two zoohoused orangutans as well as six chimpanzees, and found little difference in their selfrecognition: individuals of both species showed spontaneous mirror-guided selfexploration of otherwise nonvisible body regions, and both used the mirror to investigate otherwise visually inaccessible marks on their bodies. In contrast, four gibbons from two species, two tufted capuchin and two spider monkeys, two liontailed macaques, a Hamadryas baboon, and three mandrills all failed to show any signs of self-recognition; instead they showed only social responses to their reflection. Suarez and Gallup (1981) confirmed self-recognition in chimpanzees and an orangutan, and reported that one chimpanzee showed self-recognition after only four days of mirror exposure. This study also used an important control procedure originally introduced by Gallup, Wallnau and Suarez (1980) in a study of rhesus monkeys: in addition to a mark applied to a normally unseen body part such as the 
124 touch unusual marks on their body as an explanation for the lack of any evidence for

125 self-recognition in the third species of great ape tested by Suarez and Gallup: lowland 126 gorillas (see below).

127 Several studies have investigated factors that might influence self-recognition

128 in great apes. Early social experience appears to be one such factor. Whereas wild-

129 born, group-raised chimpanzees responded to their reflection in the same fashion as in 130 Gallup’s (1970) study, laboratory-born chimpanzees raised in isolation from an early 131 age failed to show any signs of self-recognition (Gallup et al. 1971). This work lent 132 support to Mead's (1934) view that the sense of self is shaped through social 133 experiences and interactions. Concerning the onset of self-recognition in human 134 infants, there is general agreement that the evidence becomes clear at around 16-24 135 months of age (Amsterdam 1972; Anderson 1984; Nielsen and Dissanayake 2004). A 136 sign-language-trained orangutan first showed convincing signs of mirror self137 recognition at the age of 3 years (Miles 1994), whereas non-sign-language trained 138 chimpanzees did so at around 2.5 years of age (Lin et al. 1992). Bard et al. (2006) 139 claim that chimpanzees may even show mirror-guided self-directed behaviors 140 suggestive of self-recognition by 24 months of age; these studies suggest a slightly 141 later ontogenetic emergence of self-recognition in great apes compared to typically 142 developing human infants. It should be noted, however, that the age 24 months 143 applied only when the definition of self-recognition was relaxed to include "any 144 mirror-guided self-touches.” (Bard et al. 2006, p. 201); mark-directed responses 145 suggested a later emergence, at 28 months. But in the largest cross-sectional study to 146 date - testing 92 captive chimpanzees - Povinelli et al. (1993) found that the capacity 147 was far more developmentally delayed, with only one chimpanzee out of 46 who 148 ranged from 2 to 6 years of age showing mirror self-recognition. Signs of self- 
149 recognition, consisting of either spontaneous mirror-guided self-exploration or

150 positive mark tests, were most commonly seen by Povinelli et al. (1993) among

151 adolescents and young adults (8-15 years), with chimpanzees in middle to later

152 adulthood showing fewer signs and less interest in their reflections. Until this

153 apparent age-related decline in cognitive ability starts to impair the capacity for self-

154 recognition, however, it appears to be a stable, enduring trait, as shown by a study of

155 two juvenile chimpanzees re-tested after a period of 1 year with no access to mirrors

156 (Calhoun and Thompson, 1988), and a re-test of 12 chimpanzees 8 years after an

157 initial assessment of their self-recognition ability (de Veer et al 2003). Using the same

158 criteria to measure self-recognition, the latter study found that $67 \%$ of the

159 chimpanzees showed the same reactions as when previously tested 8 years earlier.

160 The ability of chimpanzees to recognize themselves under different conditions of

161 mirror-image stimulation was reported by Kitchen et al. (1996). Six captive female

162 chimpanzees aged 7 to 14 years were presented with regular, convex, concave and

163 triptych (producing three images) mirrors. After confirming that all six apes passed

164 the mark test, the authors observed mirror-guided self-referenced behaviors during the

165 first exposure to all three kinds of distorting mirrors, which they concluded was

166 evidence of "a level of abstractional ability” with regard to their self-awareness.

167 It should be noted that, just as in humans, not all chimpanzees show evidence

168 of self-recognition (Gallup 1997; Gallup et al 2011). It is conceivable that intellectual

169 and/or personality-related factors might influence the initial responses shown toward

170 the reflection (e.g., aggression, submission, affiliation) in all species of great apes,

171 and also contribute to individual differences in whether the transition from social to

172 self-directed behavior eventually emerges. 


\section{Self-recognition in bonobos}

179 Responses to mirror-image stimulation by bonobos - the great ape species most 180 closely related to chimpanzees - were first described in 1994 (Hyatt and Hopkins 181 1994; Westergaard and Hyatt 1994). The majority of the bonobos tested showed 182 considerable interest in their reflection, and performed many more self-directed 183 behaviors in mirror-present than mirror-absent sessions; their behaviors were largely 184 indistinguishable from chimpanzees tested in similar conditions. In another study, several members of a group of zoo-housed bonobos engaged in spontaneous mirrorguided self-directed behaviors such as picking their nose and eye region, i.e., using the reflection to investigate normally unseen body parts, and these behaviors were

188 shown on the first exposure to the mirror (Walraven et al. 1995). Although no mark tests were conducted in these studies, it seems clear that like chimpanzees, bonobos readily used the mirror to examine and inspect otherwise unobservable body parts, and thus showed that they recognize themselves on the basis of "compelling instances" of self-exploration as set out by Povinelli et al. (1993, p. 351).

\section{The gorilla enigma}

195 Given their phylogenetic closeness to chimpanzees and humans, the absence of evidence for self-recognition in gorillas reported by Suarez and Gallup (1981) was

197 unexpected. Like other great apes tested by Suarez and Gallup, the gorillas initially

198 directed social responses to their reflection, a tendency that decreased across exposure 
days. However, unlike chimpanzees and orangutans, none of the gorillas showed spontaneous mirror-guided self-exploration. Despite an additional six days of exposure to the mirror, during the mark test the gorillas showed avid interest in the control mark on their wrist, but none of them investigated the mark on their brow that 203 could only be seen in the mirror.

Another failure to find evidence of self-recognition in zoo-housed gorillas was reported by Ledbetter and Basen (1982), who gave each of a 10-year-old adult male and an 11-year-old female almost 400 hours of mirror exposure. The male in particular showed social responses - notably aggression - toward his reflection. Although both individuals habituated to the mirror, no signs of self-recognition were observed either in the form of spontaneous mirror-guided self-exploration or during a

210 formal mark test. Another two laboratory-housed gorillas showed very few social

211 responses toward their reflection and no mark-directed touching in a mark test

212 (Swartz \& Evans, 1994). In an attempt to facilitate the emergence of self-recognition in two adult zoo-

214 housed gorillas, Shillito et al. (1999) presented each ape with an angled-mirror 215 apparatus inspired by Anderson and Roeder (1989) that prevented them from making 216 direct eye contact with the reflection. It had been suggested that due to gorillas’ 217 natural aversion to direct gaze, insufficient exploration of the reflected face could 218 account for their failure to learn that they themselves were the source of the reflection.

219 However, the gorillas never showed mirror-guided self-exploration during the angled 220 mirror exposure period (approximately 45 min per day for 33 days), nor did they 221 touch the mark on their head during a mark test. In contrast, both gorillas showed 222 extensive interest in marks on their wrists, indicating that their failure to investigate 223 the mark on their head in was not due to a general lack of interest in such marks. 
224 Replacing angled mirrors with a flat mirror and eliminating possible interference due

225

226

227

228

229

230

231

232

233

235

236

237

238

239

240

241

242

243 to the presence of human observers by conducting observations via video cameras made no difference: neither gorilla showed convincing signs of self-recognition.

Do the above studies show that, despite belonging to the primate family that is genetically closest to humans, gorillas are incapable of recognizing themselves in a mirror? There are claims for self-recognition in some individual gorillas. The American Sign Language-trained gorilla Koko was reported to groom her face, pick at her teeth and adorn herself in front of mirrors from the age of 3.5 years. When marktested at 19 years of age, Koko almost never touched a target area of her head during sham-mark sessions, but did so almost 50 times when she was marked and could see herself in the mirror (Patterson and Cohn 1994). Those authors also described a 22year-old zoo-housed male gorilla showing mirror-guided self-directed responses especially when his caretaker held the mirror, and Swartz and Evans (1994) claim that he responded positively on a mark test. Members of a zoo-housed group of gorillas were described as showing mirror-guided self-directed behaviors, and two individuals with marks on their face wiped the mark when looking in the mirror; (Parker, 1994) concluded that there were striking similarities in the responses of gorillas and chimpanzees to their reflections. A more strictly controlled marking procedure conducted on a 17-year-old male zoo-housed gorilla (“Xebo”) revealed significantly more mark-directed responses in the presence of the mirror than when there was no mirror present. As this positive outcome was obtained following an instance of manipulating his face while looking in the mirror, the authors concluded that gorillas are indeed capable of self-recognition (Posada and Colell 2007). In another case study using a sham-marking control procedure, a 45-year-old male gorilla (Otto) showed the highest frequency mark-directed behaviors when the 
mirror was present (Allen and Schwartz 2008), although he showed no mirror-guided self-explorations. Interestingly, neither Xebo nor Otto directed social responses toward their reflection when the mirror was first introduced. Another adult male gorilla ("Mopie”), who had failed to show any sign of self-recognition when tested by Shillito et al. (1999), was given additional exposure to his reflection and then tested using variants of the mark test (Shumaker and Swartz, 2002). Following training to peel colored stickers off the walls of his enclosure or his own body in exchange for a food reward, Mopie discovered a sticker on his head after looking in the mirror; he removed this sticker and exchanged it for food. When stickers were replaced by a beam from a laser pointer, Mopie soon learned to touch laser spots to receive rewards, and he touched one spot that appeared below his chin and that was visible only in the mirror; however, he did not respond to a laser spot on his head. Training was also used in a study of a 26-year-old female gorilla who learned

262 how to use a mirror to solve a discrimination task. She then reportedly passed a

263 version of the mark test, though few details were given (Nicholson and Gould 1995).

264 Finally, in a study consisting of a single mirror presentation to members of 12

265 nonhuman primate species, mirror-guided self-directed responses were reported in all

266 four great apes species (chimpanzees, bonobos, gorillas and orangutans) (Inoue-

267 Nakamura, 1997), but the report is short on details and no mark tests were conducted.

268 In summary, although the evidence for self-recognition is mixed and less compelling

269 for gorillas than for other great apes, the basic underlying capacity may be present in 270 some individuals. It is possible that gorillas may be more susceptible to experiential 271 and/or personality constraints on the spontaneous and unambiguous expression of 272 self-recognition. Interestingly, in a cross-cultural study of toddlers living in four 273 different sociocultural contexts, Kärtner et al. (2012) found that cross-cultural 
274 differences in children's self-recognition behaviors was largely related to caretakers'

275 emphasis on individuality and autonomy of the child. Although some researchers

276 have assessed the role of maternal style in great apes on the behavioral development

277 of offspring (e.g., Hemelrijk and de Kogel 1989; De Lathouwers M, Van Elsacker L

278 2004), potential effects on self-recognition have not yet been addressed. Povinelli

279 (1994) suggested that unusual interventions such as enculturation and sign-language

280 training might facilitate the emergence of otherwise dormant cognitive structures

281 supporting the capacity for self-recognition in gorillas. It has also been argued that the

282 capacity for self-recognition in gorillas may be in the process of being lost due to

283 evolutionary changes in gorilla socioecology that that no longer put a premium on

284 mental state attribution in the context of competition for reproductive opportunities

285 (Gallup, 1997). In concluding the review of the literature on gorillas, we note that in

286 contrast to the situation for chimpanzees and orangutans, there is a marked lack of

287 video evidence showing compelling self-recognition in gorillas. In view of its

288 importance we urge those in possession of such material to make it publically

289 available.

\section{The search for self-recognition in other primates}

292 Gallup (1970) assessed mirror-image reactions not only in chimpanzees but also in

293 members of two Old World monkey species, rhesus and stumptailed macaques. Upon

294 initial exposure to their reflection the monkeys behaved much like the chimpanzees,

295 showing strong but diminishing interest across days and initially frequent but

296 declining social responses. Unlike chimpanzees, however, the monkeys never used

297 the mirror to inspect normally unseen parts of their body, and none tried to touch the

298 mark on their head when they saw their reflection during the mark test. These striking 
ape-monkey differences in mirror-guided self-directed behavior led other researchers to begin searching for self-recognition in non-great ape primates. Multiple interventions and manipulations have been tried in attempts to obtain evidence that monkeys are capable of realizing that their behavior is the source of the behavior depicted in the mirror. In a previous review of "challenges" in self-recognition research on primates we summarized the various interventions and manipulations used in the first three decades of the field (Anderson \& Gallup 1999). Procedures have included starting exposure to mirrors at a very early age (from birth or shortly thereafter), prolonging exposure to months or even years, allowing monkeys physical access instead of just visual access to mirrors, providing portable mirrors, using multiple fixed and/or angled mirrors, and allowing monkeys to see not only their own reflections but also those of other members of their group. Various combinations of these procedures have been used with bushbabies, lemurs, marmosets and tamarins, squirrel monkeys, capuchin monkeys, talapoin monkeys, baboons and several species of macaques, but none has resulted in any prosimian or monkey showing compelling and reproducible evidence that it recognized its own reflection.

\section{Gibbons and siamangs}

Primates of the family Hylobatidae (gibbons and siamangs) are estimated to have diverged from the great ape lineage 16-18 million years ago, and from macaques 29 million years ago (Carbone et al. 2014). From a cognitive evolutionary perspective these so-called lesser apes are often seen as a crucial intermediate case between Old World monkeys and great apes. Lethmate and Dücker (1973) reported only social responses to a mirror, and no self-directed responses in four zoo-housed gibbons belonging to two species. Inoue-Nakamura (1997) also reported no self-directed 
324 responses in a pair of white-handed gibbons. In a study of mirror-image reactions in

325 nine white-handed gibbons and one gibbon-siamang hybrid, Hyatt (1998) found no

326 mark-directed behaviors during a mark-test, despite four of the gibbons receiving an

327 additional 400 hours of mirror-image stimulation before the test. Ujhelyi et al. (2000)

328 exposed three gibbons of three different species to a mirror in intermittent periods for

329 up to a total of 10 days. Upon initial exposure the three individuals showed a range of

330 reactions including some social behaviors. However, none of the gibbons responded

331 to marks on their head in modified mark tests.

There has been one claim that siamangs show self-recognition (Heschl and

333 Fuchsbichler, 2009). Following a negative mark test, the behavior of two 7-year-old

334 siamangs toward a mirror was studied over a 90-day period. The authors reported a

335 total of seven and five "truly self-referring behaviors in front of the mirror" for the

336 male and female, respectively (p. 224). However, these behaviors were merely self-

337 referenced behaviors that often occur in the absence of a mirror (e.g., scratching the

338 head or face); the authors labeled them as "truly self-referring" simply because the

339 siamangs were looking at the mirror for longer than $3 \mathrm{sec}$ when they were performed.

340 It is noteworthy that most of the instances consisted of self-scratching, which is

341 widely accepted to be an indicator of increased tension or anxiety (Maestripieri et al.

342 1992) and often occurs in non-self-recognizing primates when they see their reflection,

343 which can be perceived as an oddly behaving conspecific (Anderson, 1994). It is also

344 unfortunate that the authors did not report similar occurrences of self-scratching of

345 other body regions while the gibbons stared at the mirror; in any case there was

346 nothing like the prolonged, careful mirror-mediated inspection of otherwise

347 nonvisible regions that is typical of chimpanzees' spontaneous self-exploration. In

348 contrast to Heschl and Fuchsbichler's claim, following an extensive series of 
experiments with three species of hylobatids including siamangs, Suddendorf and Collier-Baker (2009) reached a quite different conclusion. Despite elaborate attempts to create incentives for passing the mark test, including the use of highly preferred cake icing as marks, all of the subjects failed the mark test, with none showing any evidence of being able to correctly decipher mirrored information about themselves.

354 On the basis of these studies we conclude that there is no strong evidence that gibbons or siamangs are capable of self-recognition.

\section{Attempts to engineer positive performance on the mark test}

358 Many investigators overlook the fact that some of the strongest evidence for self-

359 recognition in humans and great apes is their use of mirrors to engage in spontaneous, 360 close inspection of normally unseen body parts. Instead, they focus their efforts into 361 getting their subjects to perform what looks like a positive mark test response.

362 Anderson and Gallup (1999) reviewed studies that included more direct

363 manipulations of monkeys' experience with their reflections with this objective in

364 mind. In this category are attempts to explicitly train monkeys to learn the 365 correspondence between the reflected environment and the real one (for example, 366 using reflections to find otherwise hidden objects), marking the subject on different 367 parts of the body over several days, progressing from directly visible body marks to 368 marks visible only via the mirror, rewarding the subject for touching marks, and 369 increasing the saliency of the marks used during mark tests. In the remainder of this 370 review we focus on some of these recent attempts to engineer self-recognition in 371 monkeys. 
374 it received considerable publicity. Hauser et al. (1995) incorrectly asserted that

375 previous studies of self-recognition in monkeys had neglected the issue of whether

376 they would be interested in any marks on their bodies, and conducted mark tests with

377 tamarins in which the monkeys' natural crest of white hair on the head was dyed a

378 different color. A total of 13 mark-directed responses were reported in 5 tamarins thus

379 marked; however, serious doubts were raised about that study's conclusions based on

380 inadequate information about inter-observer reliability, whether the monkeys also

381 touched their dyed crest when the mirror was absent, and whether they repeatedly

382 investigated their dyed crest (testing was halted as soon as any mark-directed

383 response was noted (Anderson and Gallup 1997, 1999). An attempt by the same

384 laboratory to replicate their finding of self-recognition in cotton-top tamarins resulted

385 in failure (Hauser et al. 2001), and since then there have been no further claims that

386 monkeys of the family Callithrichidae are capable of self-recognition. Indeed in one

387 modification of the mark test, a chocolate-flavored cream was used to increase

388 marmoset monkeys' motivation to locate the mark on their head, but no marmosets

389 used their reflection to investigate the mark; in fact some individuals tried to lick the

390 chocolate mark in the mirror (Heschl and Burkart 2006). If there is a lesson to be

391 learned from the case of the cotton top tamarins, it is that studies of visual self-

392 recognition need to be especially careful about procedural aspects such as inter-

393 observer reliability, comparing behaviors in the presence and absence of mirrors,

394 comparing behaviors while looking at the mirror versus looking elsewhere, and the

395 validity of the behavioral parameters recorded, including frequency and durations.

396 In the most recent attempt to engineer self-recognition in monkeys, Chang et

397 al. (2015) used a training procedure with rhesus monkeys that they claim resulted in

398 “mirror-induced self-directed behaviors resembling mirror self-recognition” (p. 1). 
399 Other authors have been quick to conclude from Chang et al.’s report that rhesus 400 monkeys appear to show the same level of self-awareness as some great apes (Toda 401 and Platt, 2015). As this study represents the newest challenge to the view that the 402 capacity for self-recognition in primates may be limited to the great apes and humans, 403 it requires close scrutiny.

404 Compared with previous attempts to train mirror self-recognition in monkeys, 405 the procedures used by Chang et al. (2015) were especially elaborate, long-drawn-out, 406 and painstaking. Training lasted for up to 38 days with literally thousands of trials, 407 and initially required that monkeys be chair-restrained and forced to confront their 408 reflection for extended periods of time. As the monkeys looked at the mirror they 409 received short bursts of laser beams focused on their faces in an attempt to produce 410 irritation. Coupled with the application of the laser beams, the monkeys were also 411 given food rewards for touching the points of irritation on their faces. As might be 412 expected from principles of conditioning, this training resulted in the monkeys 413 eventually learning this simple association and reacting to marks they saw in the 414 mirror by touching their faces and looking at their fingers - much as they would when 415 encountering other learned sources of irritation or injury. It is important to recall that in designing the mark test, Gallup (1970) took

417 careful and detailed steps to ensure that the chimpanzees would not know they had 418 been marked and would be unable to detect the marks without a mirror. First, the 419 chimpanzees were anesthetized and rendered unconscious prior to the application of 420 the marks so they would have no information about having been marked. Second, the 421 marks were strategically placed on the top of an eyebrow ridge and the opposite ear in 422 such a way that the marks could not be seen without a mirror. Finally, the dye was 423 chosen to be free from any telltale tactile or olfactory cues, so that once the dye had 
424 dried and the chimpanzees recovered from anesthesia in the absence of a mirror there

425 would be no way for them to know about the existence of the strange red marks on

426 their faces. Similar to other authors who have tried to engineer self-recognition in

427 monkeys (Heschl and Burkart 2006; Roma et al. 2007; Rajala et al. 2010), Chang et al.

428 (2015) did just the opposite. Their monkeys were given extensive and focused

429 experience with the marks and underwent prolonged periods of explicit training with

430 reinforcement to touch these and other marks before being tested for self-recognition.

431 Our view is that what Chang et al. (2015) accomplished as a consequence is a trained

432 simulation of self-recognition, rather than self-recognition itself, analogous to

433 somebody being taught the correct responses to questions on an intelligence test and

434 thereby receiving a higher score, but without any fundamental change in their

435 underlying intelligence. As we pointed out in a critique of a previous paper claiming

436 to demonstrate self-recognition in rhesus monkeys based on a different source of

437 irritation (Anderson and Gallup, 2011), to be a valid test of self-recognition the mark

438 must not only be previously unseen and unfelt, it must be unknown (but see Bard et al.

4392006 for an alternative view).

440 It is noteworthy that following their training with lasers and extensive

441 reinforcement, Chang et al.'s (2015) monkeys failed to distinguish between laser

442 marks projected to the wall of their cage and to parts of their body that they could see

443 directly: they similarly touched both, suggesting that they had not learned to

444 distinguish one from the other and were only doing what they had been trained to do.

445 Rather than showing the monkeys understood they were seeing themselves in the

446 mirror, these observations imply that their bodies were simply being treated as

447 another part of the environment, to be responded to for reward as dictated by their

448 training history. By contrast, with no coaxing or training whatsoever chimpanzees 
449 often come to spontaneously use mirrors to investigate and manipulate features of

450 their body they have not seen before; they make faces at the mirror, inspect the inside

451 of their mouth, and/or use the reflection to investigate their ano-genital area. It is

452 notable that none of Chang et al.'s rhesus monkeys showed similar patterns of

453 spontaneous self-exploration, nor have any other monkeys.

It is interesting to compare the videotaped instances of ostensible mirror-

induced self-directed behavior presented by Chang et al. (2015) and readily available

video clips of chimpanzees responding to mirrors. The behaviors are quite different.

Unlike the rich, impromptu series of attempts by chimpanzees to manipulate and investigate things about themselves discovered in the mirror, the instances described as self-directed in the rhesus monkeys are simpler and stereotyped, including

“checking their own bodies or pulling their own face or head hair” (p. 215). In monkeys with visual and tactile cues that could be used to detect the presence of these marks in the absence of a mirror; this invalidates these demonstrations and is clearly at variance with most of the work done with apes.

467 rhesus monkeys over an extended period of time. One question that might be asked is 468 how they would react toward their reflection after some time with no mirror present.

469 Studies have shown that in macaques although the tendency to treat the reflection as 470 another animal eventually habituates, simply removing the mirror for several days or 471 even moving it from one side of the cage to the other can trigger a dramatic

472 reinstatement of social responses toward the reflection; this even occurs in rhesus 473 monkeys reared in front of mirrors all their lives (Gallup and Suarez 1991). If Chang 
474 et al.’s monkeys also show a resurgence of social responses, the case for self-

475 recognition would be substantially weakened. As noted earlier, the capacity for spontaneous self-recognition is stable in chimpanzees even after years with no intervening exposure to their reflection. Trying to engineer self-recognition through extensive training is not

479 fundamentally different from attempts to program robots in the presence of mirrors to superficially go through some of the same movements involved in self-recognition (Gold \& Scassellati, 2009). Whatever engineers and computer scientists get robots to do, they are clearly doing it while circumventing what it is that underpins this evolved, natural capacity in humans and great apes. Merely simulating certain features of selfrecognition through training/programing does not mean that the underlying mechanisms are the same, similar, or even remotely related (Gallup et al. 2011).

\section{Neuropsychological considerations}

Another interesting difference in self-awareness between chimpanzees and monkeys was described by Menzel et al. (1985). Mirror-experienced chimpanzees and

490 rhesus monkeys were given the task of finding hidden food on the other side of an opaque barrier by monitoring the reflection of their own hand in a mirror. Unlike the chimpanzees, who solved the problem with ease, the rhesus monkeys failed. Indeed,

493 they vocalized and threatened their hand when they saw it approach the food in the 494 mirror - as if it were the hand of another monkey. Studies with humans show that 495 when the right cortical hemisphere is temporarily deactivated with sodium amobarbital, people often mistake their hand as belonging to someone else (Meador et al. 2000), reminiscent of rhesus monkeys. Furthermore, humans whose faces were morphed in a 50/50 ratio with the face of a famous person report seeing the famous 
499

500

501

502

503

504

505

506

507

508

509

510 511 clarified.

512

513

514

515

516

person's face when their right hemisphere is anesthetized, but see their own face when the left hemisphere is anesthetized (Keenan et al. 2001). The same is true for

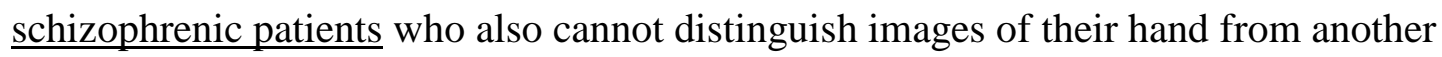
person's hand, and people with premorbid schizophrenic traits who exhibit right hemisphere deficits for recognizing their faces and deficits for picking self-descriptive adjectives (Platek et al. 2002; 2003). Damage to the right hemisphere has also been implicated in mental state attribution deficits and impaired autobiographical memory (see Gallup et al. 2003). Right hemisphere damage likewise leads to deficits in ownership and agency of body parts (Feinberg \& Keenan, 2005). Data such as these implicate the existence of self-processing mechanisms in the right side of the human brain. The extent to which homologous mechanisms exist in the brains of selfrecognizing great apes compared to non-self-recognizing monkeys remains to be

Two recent comprehensive reviews exemplify the growing interest in the neuropsychological basis for self-recognition. One consists of a thorough and detailed account of evidence showing specific neural anatomical features that distinguish primate species that can recognize themselves in mirrors from those that cannot (Butler and Suddendorf, 2014). The other involves an ALE meta-analysis of fMRI studies of self-recognition and theory of mind in humans (van Veluw and Chance, 2014), which identifies specific areas of the brain that are especially active under conditions of self-face identification. Consistent with predictions made long ago based on the hypothesis that self-awareness is what makes mental state attribution possible (Gallup, 1982), there is mounting evidence for considerable overlap between brain areas linked to self-recognition and those that have been implicated in the 
523 capacity to take into account what other people know, want or intend to do; i.e.,

524 theory of mind.

Finally, we could use Menzel’s paradigm to make another testable

526 prediction. If Chang et al.'s (2015) trained monkeys have achieved an integrated

527 sense of self-awareness as a consequence of extensive somatosensory training, then

528 they ought to be able solve Menzel's problem with ease or at least much faster than

529 macaques with no such training (Anderson, 1986; Itakura, 1987).

\section{Conclusions}

532 In the final analysis, the results of any study must be independently replicated by

533 other scientists in order for the findings to be considered reliable. The demonstration

534 of mirror self-recognition in chimpanzees, orangutans and humans has been replicated

535 many times by different investigators all over the world (for a review see Gallup et al.

536 2011). In contrast, the track record for claims of self-recognition in other species has

537 not been encouraging. Single published reports of mirror self-recognition in one

538 elephant that failed on a re-test (Plotnik et al. 2006), one dolphin (Reiss \& Marino

539 2001), and two magpies (Prior et al. 2008) have yet to be replicated. Indeed, recent

540 evidence with other corvids suggests that apparent instances of mirror self-recognition

541 by magpies may be an artifact of tactile cues (Soler et al. 2014). And in the case of

542 cotton-top tamarins (Hauser et al. 1995) an attempt to replicate the original positive

543 results completely failed (Hauser et al. 2001).

544 In conclusion, it is important to stress that without strong corroborating

545 evidence, training-induced performances that merely mimic or resemble behavior

546 spontaneously seen in other species tell us little about the cognitive abilities

547 underlying such behaviors. While interesting, the results presented by Chang et al. 
548 (2015) are not compelling evidence that rhesus monkeys are capable of self-

549 recognition. It is important to recall that mirror self-recognition per se was not

550 selected for in evolutionary history. Instead, mirror self-recognition is an expression

551 of an underlying sense of self that allows individuals to engage in other cognitive and

552 emotional acts such as empathy, reconciliation, consolation, and perspective-taking. It

553 is therefore reasonable to ask, for example, whether monkeys trained to show

554 behaviors that resemble passing the mark test also then show any of those other signs

555 of social intelligence that are characteristic of naturally self-recognizing species. If

556 they do not, it remains unclear what theoretical advances emerge from efforts to train

557 “mirror-induced self-directed behaviors resembling mirror self-recognition” (p. 1). Of

558 equal importance is whether claims of finding self-recognition in species hitherto

559 considered incapable can be replicated by other investigators.

560

561

562 References

563 Allen M, Schwartz BL (2008) Mirror self-recognition in a gorilla (Gorilla gorilla gorilla). J Integr Biosci 5:19-24

565 Amsterdam B (1972) Mirror self-image reactions before age two. Develop Psychobiol $5: 297-305$

567 Anderson JR (1984) The development of self-recognition: a review. Develop

$568 \quad$ Psychobiol 17:35-49

569 Anderson JR (1986) Mirror-mediated finding of hidden food by monkeys (Macaca tonkeana and M. fascicularis). J Comp Psychol 100:237-242

571 Anderson JR (1994) The monkey in the mirror: A strange conspecific. In Parker ST, 
Mitchell RW, Boccia ML (eds) Self-awareness in animals and humans: developmental perspectives. Cambridge University Press, New York, pp 315329

Anderson JR, Gallup GG Jr (1997) Self-recognition in Saguinus? A critical essay. Anim Behav 54:1563-1567

Anderson JR, Gallup GG Jr (1999) Self-recognition in nonhuman primates: Past and future challenges. In: Haug M, Whalen RE (eds) Animal models of human emotion and cognition. American Psychological Association, Washington DC, pp 175-194

Anderson JR, Gallup, GG Jr (2011) Do rhesus monkeys recognize themselves in mirrors? Am J Primatol 73:603-606

Anderson JR, Roeder JJ (1989) Responses of capuchin monkeys (Cebus apella) to different conditions of mirror-image stimulation. Primates 30:581-587

Bard KA, Todd BK, Bernier C, Love J, Leavens DA (2006) Self-awareness in human

Butler D, Suddendorf T (2014) Reducing the neural search space for hominid cognition: What distinguishes human and great ape brains from those of small apes? Psychon Bull Rev 21:590-619

591 Calhoun S, Thompson RL (1988) Long-term retention of self-recognition by chimpanzees. Am J Primatol 15:361-365

593 Carbone L et al. (2014) Gibbon genome and the fast karyotype evolution of small apes. Nature 513:195-201

595 Chang L, Fang Q, Zhang S, Poo M, Gong N (2015) Mirror-induced self-directed 
behaviors in rhesus monkeys after visual-somatosensory training. Curr Biol $25: 212-217$

De Lathouwers M, Van Elsacker L (2004) Comparing maternal styles in bonobos (Pan paniscus) and chimpanzees (Pan troglodytes). Am J Primatol 64:411423

601 De Veer MW, Gallup GG Jr, Theall LS, van deb Bos R, Povinelli DJ (2003) An 8602 year longitudinal study of mirror self-recognition in chimpanzees (Pan troglodytes). Neuropsychologia 41:229-234

604 Feinberg TE, Keenan JP (2005) Where in the brain is the self? Consc Cogn 14:661605 678

606 Gallup GG Jr (1968) Mirror-image stimulation. Psychol Bull 70:782-793

607 Gallup GG Jr (1970) Chimpanzees: Self-recognition. Science 167:86-87

608 Gallup GG Jr (1982) Self-awareness and the emergence of mind in primates.

$609 \quad$ American J Primatology 2: 237-248.

610 Gallup, GG Jr (1997) On the rise and fall of self-conception in primates. Ann N Y Acad Sci 818: 73-84

612 Gallup GG Jr, Anderson JR, Platek SM (2003) Self-awareness, social intelligence and schizophrenia. In Kircher T, David A (eds) The self in neuroscience and psychiatry. Cambridge University Press, Cambridge UK, pp 147-165

615 Gallup GG Jr, Anderson JR, Platek SM (2011) Self-recognition. Gallagher S (ed) The Oxford handbook of the self. Oxford University Press, Oxford, pp 80-110.

617 Gallup GG Jr, McClure MK, Hill SD, Bundy RA (1971) Capacity for self-recognition in differentially reared chimpanzees. Psychol Rec 21:69-74

619 Gallup GG Jr, Povinelli DJ, Suarez SD, Anderson JR, Lethmate J, Menzel EW Jr 
(1995) Further reflections on self-recognition in primates. Anim Behav

621 50:1525-1532.

622 Gallup GG Jr, Suarez SD (1991) Social responding to mirrors in rhesus monkeys (Macaca mulatta): Effects of temporary mirror removal. J Comp Psychol 105:376-379

Gallup GG Jr, Wallnau LB, Suarez SD (1980) Failure to find self-recognition in mother-infant and infant-infant rhesus monkey pairs. Folia Primatol 33:210219

Gold K, Scassellati B (2009) Using probabilistic reasoning over time to selfrecognize. Robot Auton Syst 57:384-392

Hauser MD, Kralik J, Botto-Mahan C, Garrett M, Oser J (1995) Self-recognition in primates: Phylogeny and the salience of species-typical features. Proc Nat Acad Sci USA 92:10811-10814

Hauser MD, Miller CT, Liu K., Gupta R (2001) Cotton-top tamarins (Saguinus oedipus) fail to show mirror-guided self-exploration. Am J Primatol 53:131-

636 Hemelrijk CK, de Kogel CH (1989) What chimpanzee mothers have more sociable infants? Behaviour 111:305-318

Heschl A, Burkart J (2006) A new mark test for mirror self-recognition in non-human primates. Primates 47:187-198

640 Heschl A, Fuchsbichler C (2009) Siamangs (Hylobates syndactylus) recognize their mirror image. Int J Comp Psychol 22:221-233

642 Heyes CM (1994) Reflections on self-recognition in primates. Anim Behav 47:909643 19

644 Hyatt CW (1998) Responses of gibbons (Hylobates lar) to their mirror images. Am J 
Hyatt CW, Hopkins WD (1994) Self-awareness in bonobos and chimpanzees: A comparative perspective. In Parker ST, Mitchell RW, Boccia ML (eds) Selfawareness in animals and humans: developmental perspectives. Cambridge University Press, New York, pp 248-253

Inoue-Nakamura N (1997) Mirror self-recognition in primates: A phylogenetic perspective. Japan Psychol Res 39:266-275

Itakura S (1987) Mirror guided behavior in Japanese monkeys (Macaca fuscata). Primates 28:149-161

654 Kärtner J, Keller H, Chaudhary N, Yovski RD (2012) The development of mirror self-recognition in difference sociocultural contexts. Monogr Soc Res Child Develop 77 (4): Serial No. 305

Keenan JP, Nelson A, O’Connor M, Pascual-Leone A (2001) Self-recognition and the right hemisphere. Nature 409:305

Kitchen A, Denton D, Brent L. (1996) Self-recognition and abstraction abilities in the 660 common chimpanzee studied with distorting mirrors. Proc Natl Acad Sci USA 93:7405-7408

Ledbetter DH, Basen J (1972) Failure to demonstrate self-recognition in gorillas. Am J Primtol 2:307-310

Lethmate J, Dücker G (1973) Untersuchungen zum Selbsterkennen im Spiegel bei Orang-utans und einigen anderen Affenarten. Z Tierpsychol 33: 248-269

Lin AC, Bard KA, Anderson JR (1992) Development of self-recognition in chimpanzees (Pan troglodytes). J Comp Psychol 106:120-127

668 Maestripieri D, Schino G, Aureli F, Troisi A (1992) A modest proposal: displacement activities as an indicator of emotions in primates. Anim Behav 44:967-979 
670 Mead GH (1934) Mind, self, and society. Chicago: University of Chicago Press

671 Meador KJ, Loring DW, Feinberg TE, Lee GP, Nichols ME (2000) Anosognosia and asomatognosia during intracarotid amobarbital inactivation. Neurology

673 $55: 816-820$

Menzel EW Jr, Savage-Rumbaugh ES, Lawson J (1985) Chimpanzee (Pan troglodytes) spatial problem solving with the use of mirrors and televised equivalents of mirrors. J Comp Psychol 99:211-217

Miles HLW (1994) Me Chantek: The development of self-awareness in a signing orangutan. In Parker ST, Mitchell RW, Boccia ML (eds) Self-awareness in animals and humans: developmental perspectives. Cambridge University Press, New York, pp 254-272

Nicholson IS, Gould JE (1995) Mirror mediated object discrimination and selfdirected behavior in a female gorilla. Primates 36:515-521

Nielsen M, Dissanayake C (2004) Pretend play, mirror self-recognition and imitation: a longitudinal investigation through the second year. Inf Behav Develop 27:342-365

Parker ST (1994) Incipient mirror self-recognition in zoo gorillas and chimpanzees. In Parker ST, Mitchell RW, Boccia ML (eds) Self-awareness in animals and humans: developmental perspectives. Cambridge University Press, New York, pp 301-397

690 Patterson FGP, Cohn RH (1994) Self-recognition and self-awareness in lowland gorillas. In Parker ST, Mitchell RW, Boccia ML (eds) Self-awareness in animals and humans: developmental perspectives. Cambridge University Press, New York, pp 273-290

694 Platek SM, Gallup GG Jr, (2002) Self-face recognition is affected by schizotypal 
personality traits. Schizophr Res 57:311-315

696

697

698

699

700

701

702

703

704

705

706

707

708

709

710

711

712

713

714

715

716

717

718

Platek SM, Myers TE,Critton SR, Gallup GG Jr (2003) A left-hand advantage for self-description: the impact of schizotypal personality traits. Schizophr Res $65: 147-151$

Plotnik JM, de Waal FBM, Reiss D (2006) Self-recognition in an Asian elephant. Proc Natl Acad Sci USA 103:17053-17057

Posada S, Colell M (2007) Another gorilla (Gorilla gorilla gorilla) recognizes himself in a mirror. Am J Primatol 69:576-583

Povinelli DJ (1994) How to create self-recognizing gorillas (but don’t try it on macaques). In Parker ST, Mitchell RW, Boccia ML (eds) Self-awareness in animals and humans: developmental perspectives. Cambridge University Press, New York, pp 291-300

Povinelli DJ, Gallup GG Jr, Eddy TJ, Bierschwale DT, Engstrom MC, Perilloux HK, Toxopeus IB (1997) Chimpanzees recognize themselves in mirrors. Anim Behav 53: 1083-1088

Povinelli DJ, Rulf AB, Landau KR, Bierschwale DT (1993) Self-recognition in chimpanzees (Pan troglodytes): Distribution, ontogeny, and patterns of emergence. J Comp Psychol 107:347-372

Premack D, Woodruff G (1978) Does the chimpanzee have a theory of mind? Behav Brain Sci 4:515-526

Prior H, Schwarz A, Gunturkun O (2008) Mirror-induced behavior in the magpie (Pica pica): Evidence of self-recognition. PLoS Biol 6(8): e202. Doi:10. 1371/journalpbio.0060202

Rajala AZ, Reininger KR, Lancaster KM, Populin LC (2010) Rhesus monkeys 

(Macaca mulatta) do recognize themselves in the mirror: Implications for the evolution of self-recognition. PLoS ONE 5(9): e12865. doi: 10.1371/journal.pone.0012865

Reiss D, Marino L (2001) Mirror self-recognition in the bottlenose dolphin: A case of cognitive convergence. Proc Natl Acad Sci USA 98:5937-5942

Roma PG, Silberberg A, Huntsberry ME, Christensen CJ, Ruggerio AM, Suomi SJ (2007) Mark tests for self-recognition in capuchin monkeys (Cebus apella) trained to touch marks. Am J Primatol 69:989-1000

Shillito DJ, Gallup GG Jr, Beck BB (1999) Factors affecting mirror behavior in western lowland gorillas, Gorilla gorilla. Anim Behav 57:999-1004

Shumaker RW, Swartz KB (2002) When traditional methodologies fail: Cognitive studies of great apes. In Bekoff M, Allen C, Burghardt GM (eds) The cognitive animal: empirical and theoretic perspectives on animal cognition. The MIT Press, Cambridge MA, pp. 335-343

Soler M, Pérez-Contreras T, Peralta-Sánchez JM (2014) Mirror-mark tests performed on jackdaws reveal potential methodological problems in the use of stickers in avian mark-test studies. PLoS ONE 9(1): e86193.

Doi:10.1371/journal.pone.0086193

Suarez SD, Gallup GG Jr (1981) Self-recognition in chimpanzees and orangutans, but not gorillas. J Hum Evol 10:157-188

Suddendorf T, Collier-Baker E (2009) The evolution of primate visual selfrecognition: Evidence of absence in lesser apes. Proc R Soc B doi: 10.1098/rspb. 2008.1754.

Swartz KB, Evans S (1994) Social and cognitive factors in chimpanzee and gorilla 
mirror behavior and self-recognition. In Parker ST, Mitchell RW, Boccia ML (eds) Self-awareness in animals and humans: developmental perspectives. Cambridge University Press, New York, pp 189-206

\section{Figure legend:}

Thompson RKR, Contie CL (1994) Further reflections on mirror-usage by pigeons: Lessons from Winnie-the-Poojh and Pinocchio too. In Parker ST, Mitchell RW, Boccia ML (eds) Self-awareness in animals and humans: developmental perspectives. Cambridge University Press, New York, pp 392-409

Toda K, Platt ML (2015) Animal cognition: Monkeys pass the mirror test. Curr Biol 25:R64-R66

Ujhelyi M, Merker B, Buk P, Geissman T (2000) Observations on the behavior of gibbons (Hylobates leucogenys, H. gabriellae, and H. Lar) in the presence of mirrors. J Comp Psychol 114: 253-262

van Veluw SJ, Chance, SA (2014) Differentiating between self and others: An ALE meta-analysis of fMRI studies of self-recognition and theory of mind. Brain Imaging Behav 8: 24-38

Walraven V, van Elsacker L, Verheyen R (1995) Reactions of a group of pygmy chimpanzees (Pan paniscus) to their mirror-images: Evidence of selfrecognition. Primates 36:145-150

Westergaard GC, Hyatt CW (1994) The responses of bonobos (Pan paniscus) to their mirror images: Evidence of self-recognition. Hum Evol 9:273-279 
767 Fig. 1 Examples of spontaneous mirror-guided exploration of normally unseen body

768 parts in chimpanzees (photos by D J Povinelli)

769

770 